\title{
Treatment of portal hypertension by subtotal splenectomy and central splenorenal shunt
}

\author{
Andy Petroianu
}

Department of Surgery, Medical School, Federal University of Minas Gerais, Belo Horizonte, MG, Brazil

\begin{abstract}
Summary: A method is proposed to reduce portal hypertension utilizing subtotal splenectomy and a central splenorenal shunt. The advantages of this method are: diversion of the splenic component of the portal circulation, creation of a shunt for the portal blood into the systemic circulation, preservation of the splenic function and correction of the manifestations of the hypersplenism.

Two cases are presented who remain well four years after surgery.
\end{abstract}

\section{Introduction}

The high morbidity and mortality of portal hypertension, due to oesophageal and gastric variceal haemorrhage, has resulted in a search for successful methods of intervention. ${ }^{1-9}$

Besides the intensive investigation to find a drug to control the high pressure in the portal system, to date, the most acceptable treatment is still surgery for the prevention of variceal rupture by reducing hydrostatic pressure within the varices. ${ }^{9}$ Sclerotherapy is a good treatment for cases of acute variceal haemorrhage, in patients with high operative risk. ${ }^{10}$ However, the follow-up of this procedure shows higher recurrent bleeding and more oesophageal and gastric complications than surgery. ${ }^{11-13}$

Two fundamental types of surgical approach have been described: those which interrupt the portal-variceal connection, $8,14,15$ and those which reduce the portal blood flow and pressure through a systemic diversion or shunt. ${ }^{1-7,12,16}$ Portalsystemic shunts or decompression procedures are usually more effective for the control of variceal haemorrhage. ${ }^{6}$ One type of procedure decreases portal blood flow by means of total splenectomy, while others create bypasses to the systemic circulation.

In this paper, we describe a surgical procedure for the treatment of portal hypertension, producing a decrease in portal blood flow by means of a subtotal splenectomy and central splenorenal shunt. ${ }^{17}$ This procedure has been used in patients

Correspondence: A. Petroianu, M.D., Ph.D., Rua Sao Paulo, 925-Apto. 802, 30170-Belo Horizonte, MG-Brazil Accepted: 16 July 1987 with schistosomatic portal hypertension. We are describing the first two cases that have a longer follow-up.

\section{Patients and methods}

A 29 year old woman and an 18 year old man, both from endemic areas of $S$. mansoni, were admitted to the Digestive Surgery Division of Hospital das Clinicas, UFMG, Brazil, with haematemesis and melaena of 9 and 4 months duration, respectively. Both had hepatosplenomegaly and were found to be bleeding from oesophageal varices. Splenoportography showed enlarged splenic veins, and intrasplenic pressure of 40 and $48 \mathrm{~cm}$ of water, respectively. Their surgical treatment is described.

The abdominal cavity was entered through a diagonal left subcostal incision, extending from the medial border of the ninth intercostal space to the midline. The splenic artery was ligated in the lesser sac after dividing the greater omentum and gastrocolic ligament. The spleen was gently displaced upward and its ligaments were divided between ligatures. (These ligatures are necessary because, in chronic portal hypertension, the splenic ligaments contain numerous hypertrophic collateral veins.) The splenic hilum was dissected, ligated with silk sutures, and the short gastric vessels were divided, sparing only the uppermost short gastrics at the cephalad pole of the spleen. The mobilized spleen could be brought into the operating field where a subtotal resection of the devascularized lower pole could be performed under direct vision. The excision began at the margins of the upper pole

(C) The Fellowship of Postgraduate Medicine, 1988 
vessels and was bevelled to the midline of the parenchyma, maintaining a wide flap of splenic capsule. Briskly bleeding vessels were ligated with chromic catgut sutures. Minor parenchymal bleeding was controlled when the free edges of the capsule were closed with continuous tight suture of two-zeros polyglycolic acid thread on a $5 \mathrm{~cm}$ needle (Figure 1). When haemostasis was assured, the remaining vascularized spleen was replaced in its normal position. The divided splenic vein was then anastomosed end-to-side to the left renal vein, using six-zeros mononylon thread (Figure 2). The abdomen was closed.

\section{Results and discussion}

On the fourth postoperative day, a splenoportogram through the exteriorized gastroepiploic vein showed patency of the splenorenal anastomosis, and a portal vein pressure of $17 \mathrm{~cm}$ of water, in both cases. Scintillation scanning revealed reduced splenic masses with normal filling. Ultrasonography showed retrocostal spleen and free communication between splenic and renal veins (Figure 3).

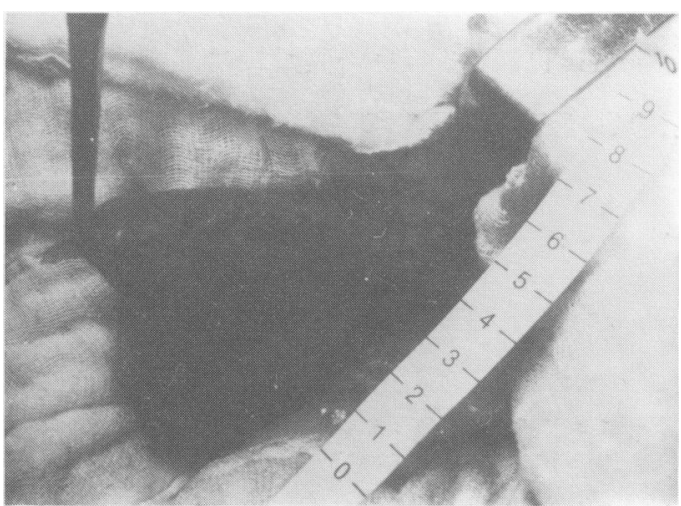

Figure 1 The spleen after subtotal resection showing the suture.

On the seventh postoperative day, the haematological examinations showed normal values, and both patients left the hospital in good condition. During the 4 years follow-up, the two patients did not present with any problem related with the disease or surgery.

The first reported segmental splenectomy performed in humans was done, in 1959, at the same hospital from which the present work is

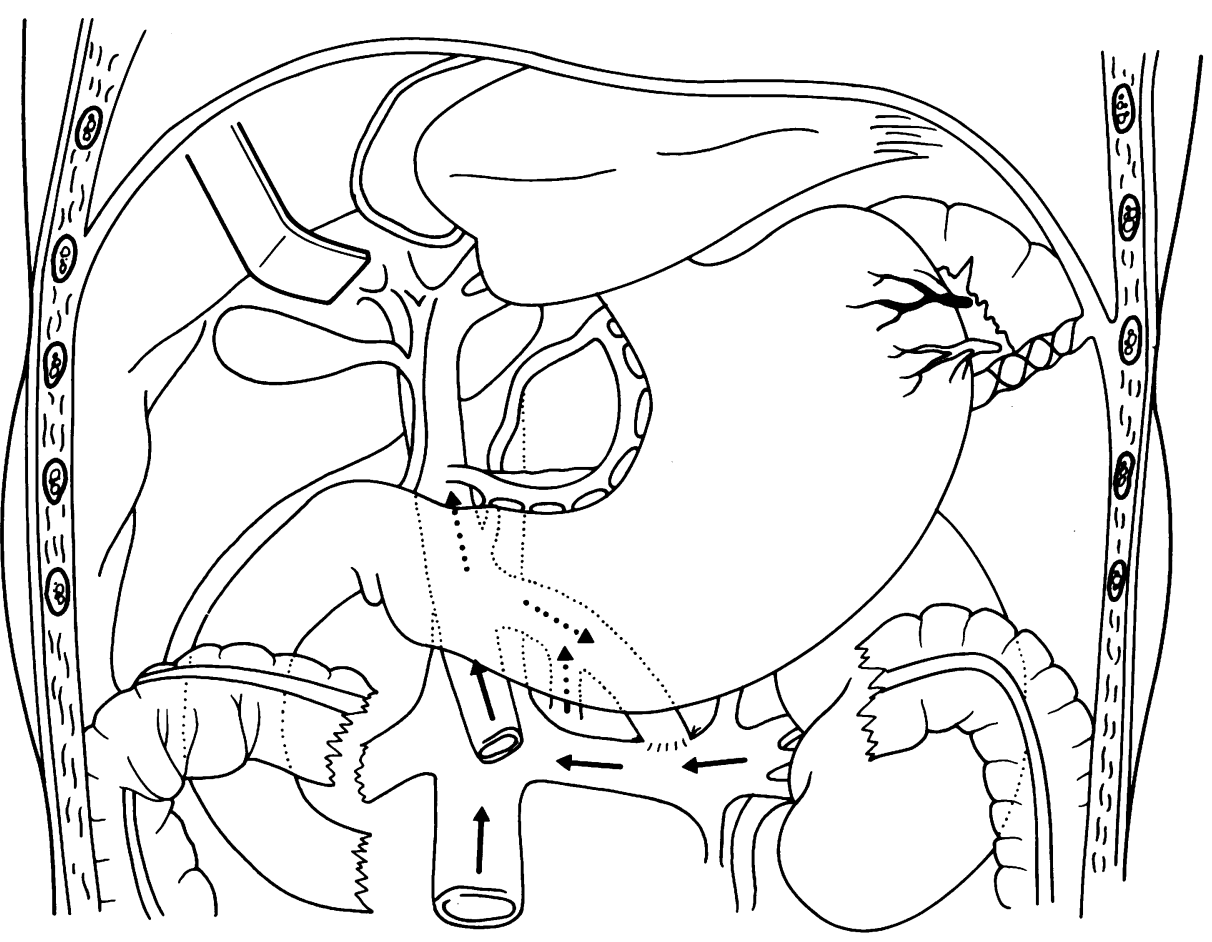

Figure 2 Sketch of the surgery showing the subtotal splenectomy and the splenorenal anastomosis. 


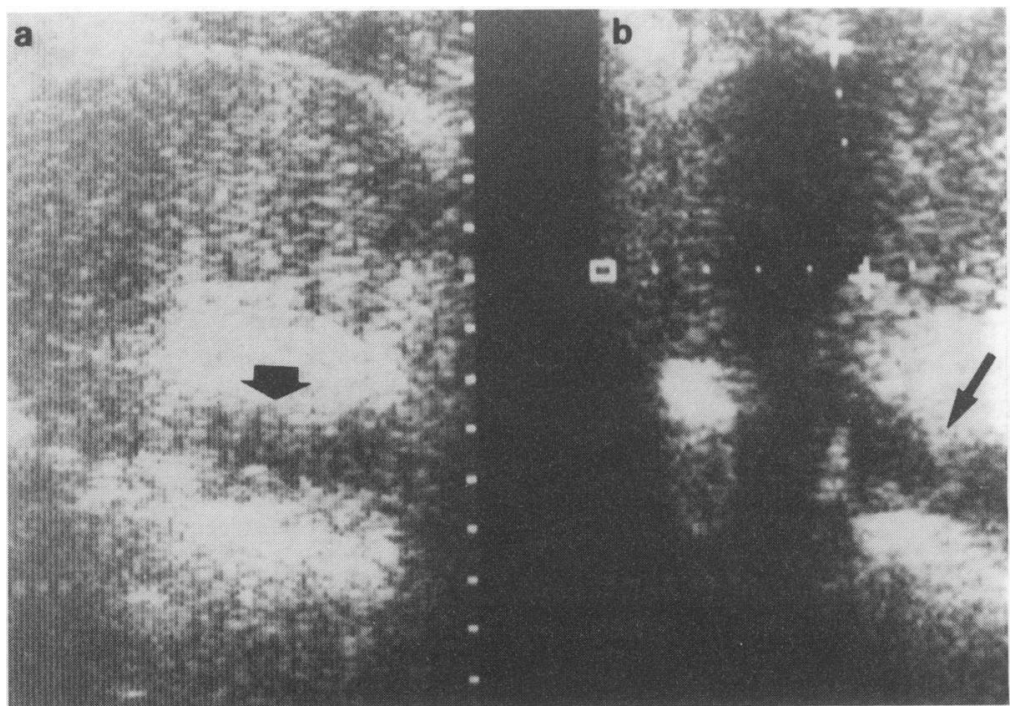

Figure 3 Abdominal echography showing: (a) splenic vein (arrow). (b) splenorenal anastomosis (arrow).

reported. ${ }^{18}$ Segmental splenectomy is preferable to total splenectomy because of the importance of the spleen to the reticuloendothelial and haematopoietic systems. Conservative splenic surgery is performed in the management of trauma and some haematological illnesses. ${ }^{19}$ The rationale for splenectomy in portal hypertension is the effort to eliminate the pancytopenia, that may exacerbate the illness. Preserving the upper pole of the spleen, as suggested here, enables the surgeon to achieve the goals of total splenectomy while maintaining splenic immunological function.

The interruption of the blood flow from the spleen to the portal vein reduces the blood volume and pressure in the portal system. The splenorenal shunt decompresses the portal system by creating a bypass into the low pressure systemic venous circulation (Figures 2, 3).

Follow-up sonography has shown that splenic dimensions did not increase substantially in the late postoperative period. Sonography was also successful in demonstrating patency of the

\section{References}

1. Whipple, A.O. The problem of portal hypertension in relation to the hepatopathies. Ann Surg 1945, 122: 449-475.

2. Blakemore, A.H. Portocaval shunting for portal hypertension. Surg Gynecol Obstet 1952, 94: 443-454.

3. Resende Alves, J.B. Operaçāo de escolha no tratamento da hipertensāo portal. J Brasil Cir 1963, 2: 1061-1067. splenorenal anastomosis ${ }^{20}$ (Figure 3). Scintillation scanning in the postoperative period indicated normal splenic filling. ${ }^{21}$

The method described herein continues to be studied carefully in order to establish its advantages in decreasing portal hypertension while maintaining a viable splenic remnant. Before any conclusion can be reached it is still necessary to confirm the preservation of splenic function and to assess the status of oesophageal varices. We also need to verify the constitutional sequelae following the portal-systemic shunt. A longer follow-up is also required to observe whether the splenic remnant will be enlarged or not by the portal disease.

\section{Acknowledgements}

We gratefully acknowledge the assistance of Dr Peter L. Geller for the revision of this manuscript.

We also thank the CNPq and CPq-UFMG for the financial support.

4. Gonzalez, E.M., San Martin J.M., Abella, P.C., Aguyo, J.L.R. \& Jelavik, D. Interposition left gastriccaval shunt using internal jugular vein autograft in the treatment of portal hypertension. $B r J$ Surg 1978, 65: 115-117.

5. Inokuchi, K., Kobayashi, M., Kusaba, A., Ogava, Y., Saku, M. \& Shüzaki, T. New selective decompression of esophageal varices. Arch Surg 1970, 100: 157-162. 
6. Henderson, J.M. \& Warren, W.D. Selective variceal decompression. Adv Surg 1984, 18: 81-115.

7. Read, R.C. Elective mesocaval interposition shunt. Contemp Surg 1986, 28: 38-47.

8. Abouna, G.M., Baissony, H. \& Menkarios, A.T. The place of Sugiura operation for portal hypertension and bleeding esophageal varices. Surgery 1987, 101: 92-98.

9. Groszman, R.J. Drug therapy of portal hypertension. Am J Gastroenterol 1987, 82: 107-113.

10. Korula, J., Balart, L.A., Radvan, G., Zweiban, B.E., Larson, A.W., Kao, H.W. \& Yamada, S.A. A prospective randomized controlled trial of chronic esophageal variceal sclerotherapy. Hepatology 1985, 5: 584-589.

11. Sarles, H.E., Sanowski, R.A. \& Talbert, G. Course and complications of endoscopic variceal sclerotherapy. Am J Gastroenterol 1985, 80: 595-599.

12. Warren, W.D., Galambos, J., Riepe, S.P. et al. Distal splenorenal shunt versus endoscopic sclerotherapy for long-term management of variceal bleeding. Ann Surg 1986, 203: 454-462.

13. Cello, J.P., Grendell, J.H., Crass, R.A., Weber, T.E. \& Trunkey, D.D. Endoscopic sclerotherapy versus portacaval shunt in patients with severe cirrhosis and acute variceal hemorrhage. $N$ Engl J Med 1987, 316: 11-15.
14. Galvāo, L. Terapēutica cirúrgica de eleiçāo na hipertensāo porta. J Brasil Cir 1963, 2: 985-997.

15. Terés, J., Baroni, R., Bordas, J.M., Visa, J. Pera, C. \& Rodés, J. Randomized trial of portocaval shunt, stapling transection and endoscopic sclerotherapy in uncontrolled variceal bleeding. J Hepatol 1987, 4: 159-167.

16. Gibson, P.R., McInnes, I.E. \& Dudley, J. The longterm effect of distal lienorenal shunt surgery on portal venous pressure. Aust $N Z J$ Surg 1986, 56: 773-776.

17. Petroianu, A. Esplenectomia parcial e anastomose esplenorrenal para o tratamento da hipertensāo portal. Rev Brasil Cir 1983, 73: 101-104.

18. Christo, M.C. Esplenectomias parciais regradas. Hospital 1959, 56: 645-650.

19. Slim, M.S., Najjar, N.E. \& Mishalany, H.G. Preservation of the injured spleen. Br J Surg 1979, 66: 671-672.

20. Moriyasu, F., Tamada, T., Miyake, T., Nakamura, T. \& Uchino, H. Ultrasonic doppler duplex study of hemodynamic changes from portosystemic shunt operation. Ann Surg 1987, 205: 151-156.

21. Armas, R., Thakur, M.L. \& Gottschalk, A. A simple method of spleen imaging with $\mathbf{T c}^{99 \mathrm{~m}}$-labeled erythrocytes. Radiology 1979, 132: 215-216. 